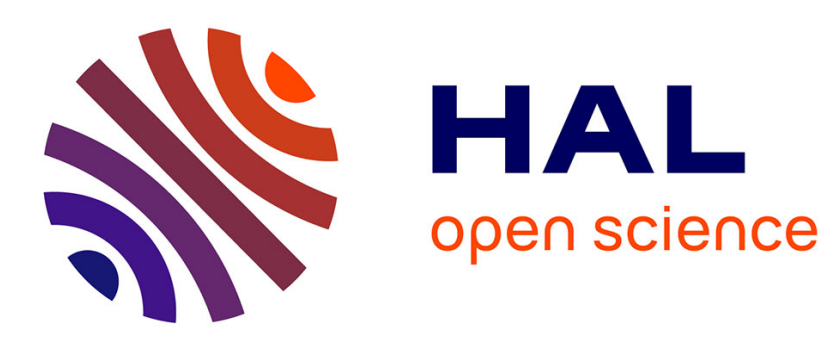

\title{
Equilibrium and Optimal Location of Warehouses in Urban Areas: A Theoretical Analysis with Implications for Urban Logistics \\ François Combes
}

\section{- To cite this version:}

François Combes. Equilibrium and Optimal Location of Warehouses in Urban Areas: A Theoretical Analysis with Implications for Urban Logistics. TRB: Transportation research record, 2019, 2673 (5), p 262-271. 10.1177/0361198119838859 . hal-03272805

\section{HAL Id: hal-03272805 https://hal.science/hal-03272805}

Submitted on 28 Jun 2021

HAL is a multi-disciplinary open access archive for the deposit and dissemination of scientific research documents, whether they are published or not. The documents may come from teaching and research institutions in France or abroad, or from public or private research centers.
L'archive ouverte pluridisciplinaire HAL, est destinée au dépôt et à la diffusion de documents scientifiques de niveau recherche, publiés ou non, émanant des établissements d'enseignement et de recherche français ou étrangers, des laboratoires publics ou privés. 


\title{
- Equilibrium and optimal location of warehouses
}

\begin{abstract}
This paper presents a structural microeconomic model of the choice of warehouse location in urban logistics. The model is theoretical and analytical. It brings the focus on operational constraints, their diversity, and their influence on costs. The location decision is modelled as a trade off between land rents (making it costly to locate close to the center of the urban area) and transport costs (which increase non linearly when the warehouse moves away from the city center.) The influence of various parameters on the optimal warehouse location is analysed. The following conclusions are drawn. First, increased demand contributes to explain logistic sprawl: when the density of operations (pick-ups and deliveries) increase in a given area; transport is more efficient, making it less necessary for warehouses to be close to the city center. Second, urban logistics is a heterogenous sector and, depending on the operational constraints, will not react homogenously to changes in economic parameters or the implementation of public policies. Third, economies of scale are identified: some implications are discussed. Fourth, the paper briefly discusses how land-use planning, regarding in particular warehouses, can help internalise some of the externalities of urban logistics.
\end{abstract}

\section{Introduction}

Urban logistics commonly refers to the systems and processes which make possible the supply of commodities in urban areas. As such, it is an essential, non substitutable economic function of cities $(1,2)$. It includes urban freight transport, as well as supply chain management insofar as it directly regards urban areas, including storage, handling and cross-docking in warehouses inside or around urban areas. The location of these warehouses is a complex, yet critical process $(3,4)$.

From a public policy standpoint, urban logistics raises a number of issues: it requires real estate, in a place where real estate is scarce; it generates traffic, in a place where roads are congested, parking space lacks, and pollution and noise are particularly harmful, due to both building configuration and the mere concentration of residents (5).

*ORCID ID 0000-0001-5658-4437, IFSTTAR, AME/SPLOTT, 14-20 bvd Newton, 77447 - Marne-laVallée, France. 
As a consequence, a reduction in the pressure that urban logistics exerts on urban areas is strongly wished for.

And yet, the beneficiaries of urban logistics, i.e., mostly, residents (either directly or through retail stores), are a particularly demanding and difficult segment to satisfy from a supply chain management perspective. Indeed, the demand is spatially and temporally dispersed, prefers frequent orders of small amounts of commodities, and values highly variety, flexibity, and, when relevant, short lead time. Thus the cost of the last mile, often estimated to be a substantial share of total logistic costs. As a consequence, urban logistics heavily relies on a large flow of small vehicles, not used at weight or volume capacity, often old and polluting.

Urban logistics is undergoing a number of trends which very probably intensify these issues. One can quote e-commerce (6), which is generally associated with small and unpredictable orders (7). Also, multi-channel distribution, where supply chains are reorganised to provide customers with several logistic alternatives, comes with a complexity which probably makes it more difficult to leverage economies of scale and use environmentally virtuous transport organisations. The impact of new technologies, services (such as the rise of instant deliveries, 8 ), and marketplaces, is currently extremely uncertain, and will have to be assessed in the long term.

This paper is focused on a specific trend: logistics sprawl. Logistics sprawl refers to the phenomenon observed in many large urban areas (although not all of them) where warehouses and logistic platforms tend to move away from the urban areas, faster than other economic activities or households (9-12). This trend is particularly alarming, as it directly reinforces the impacts of urban logistics, by making vehicles cover longer distances to provide the same service(13). It is also not a fatality: compared to some of the trends quoted above, which essentially stem from technological or organisational innovations, and sometimes seem quite inescapable, logistic sprawl is a standard land use planning issue. As such, it is governed by transport economics and urban economics, and it can be addressed by policy instruments such as land use planning and regulation.

However, before policy recommandations are suggested, a thorough understanding of the issue is necessary. The objective of this paper is to contribute to this understanding by the means of a microeconomic model. The model considers commodities delivered in an urban area by vehicles starting from a logistic platform located at the outskirt of the urban area. The location of the logistic platform is assumed to be a tradeoff between land rent and transport costs. Particular attention is paid to the modelling of transport costs (14). Indeed, the structure of transport costs results from various operational constraints; several distinct regimes (i.e. typs of constraints) are analysed and compared. The sensitivity of the location of the logistic platform to the model's parameters is investigated. The (private) optimum location of the logistic platform is also investigated, with the introduction of a number of externalities.

The originality of the paper relies on the detailed representation of the transport cost structure and the distinction and explicit representation of several operational constraints. This diversity of these constraints illustrates how difficult it can be to measure the overall performance of urban logistics, or lack thereof: simply measuring it with an average loading factor, for example, can be strongly misleading. Economies of scales are identified regarding transport costs: some implications are briefly discussed. The paper also contributes to understanding the drivers of the location of logistic platforms, 
and confirms the role of land rents (especially land rent gradients) in the process. Finally, it discusses the extend to which land use planning actions can correct some of the market failures of urban logistics.

The paper proceeds as follows: Section 2 presents the modelling assumptions, and derives the total cost function, under different sets of assumptions. Section 3 presents and discusses the model's properties. Section 4 concludes the paper.

\section{Model presentation}

This section begins with a brief presentation of urban logistics, based on the example of the urban area of Paris (Section 2.1). Then, the main modelling assumptions are presented (Section 2.2). Finally, the model is elaborated in Section 2.3.

2.1 A brief description of urban logistics, based on the case of the urban area of Paris, France

Before diving into the specifics of the model, it is useful to present a few facts about freight transport operations regarding urban areas. Consider a shipper sending commodities towards a given receiver (both can be firms or individuals, or households). There are very basically two options to transport those commodities: the first one is direct transport, where the vehicle loads the shipment at the origin, carries it to the destination and unloads it (full truckload - FTL), possibly with a few other shipments going from similar origins to similar destinations (partial truckload).

The second is massified transport (Less Than Truckload - LTL), where the shipment is picked up together with other shipments in the vicinity, regardless of destination, brought to a warehouse, or a cross-docking platform, where it is unloaded, sorted, loaded onto another vehicle, carried toward another cross-docking platform close to the destination area, where it will, again, be unloaded, sorted, and loaded in a vehicle, to be delivered it a certain area, together with other shipments.

The first option is adapted for rather large flows of not too time sensitive commodities, whereas the second option is relevant for smaller flows of more time sensitive commodities (consistently with the theory developed in (15), and confirmed empirically in this specific case in (16)).

The second organisation is prevalent in urban logistics. Consider the case of the urban area of Paris, France $\left(17,175 \mathrm{~km}^{2}, 12.4\right.$ million inhabitants). A urban goods movement survey was realised in this area in 2010-2012; it reveals that $38 \%$ of the movements (pickups or deliveries) are realised by car or light commercial vehicles, $29 \%$ by vans, $23 \%$ by straight trucks, and only $9 \%$ in semi-trailers (17). Parcel deliveries are mainly associated with vans and small LCVs, while pallets are more generally delivered by straight trucks $(18,19)$. Also, many of the movements observed in the survey which were made by semi-trailers are deliveries toward large retail centers or warehouses, which in turn emit movements of smaller vehicles, with an average ratio of three to four outgoing vehicles for one incoming vehicle (17). Finally, it should be noted that the survey is strongly oriented towards B2B flows and therefore misses an unknown share of B2C flows (but estimated to amount to about a third of all movements 
in 8), which tends to strengthen the above statement again. It is therefore legitimate to state that the share of LTL transport is overwhelming in the case of the urban area of Paris, and possibly in other large urban areas as well.

\subsection{Main modelling assumptions}

Consider a given large urban area. Given the previous discussion, the focus is brought on shipments handled in a warehouse inside or at the outskirt of the urban area before being delivered. Shipments transported in partial or full truckload are disregarded. Courier activity is ignored as well.

By assumption, every shipment delivered in the urban area undergoes the sequence of operations illustrated in Figure 1. In this figure, the shipment of interest is the small red block stored in a warehouse (visible at the left-hand side of the picture), ordered by a given receiver (depicted by a red cross at the right-hand side), in a given urban area where other shipments will be delivered and picked up. For a delivery, the sequence of operations is as follows:

a) the shipment is loaded into a large vehicle (typically a semi-trailer), carried toward a cross-docking platform.

b) the shipment is unloaded, sorted and loaded in a smaller vehicle.

c) the smaller vehicle reaches the area where the deliveries and pick-ups will be made.

d) the shipment is delivered, during a round where other operations are realised.

The distinction between the approach and return movements, on one hand, and the intermediate movements on the other hand is directly drawn from (20). The gray, dashed lines illustrate the other vehicles coming to the warehouse or leaving it, from or towards other places.

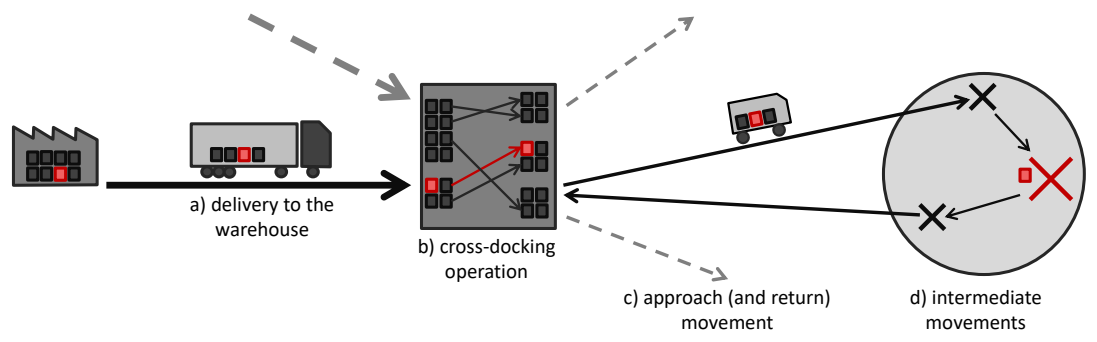

Figure 1: Operations sequence

Another set of assumptions should be discussed here, regarding the operational constraints in urban logistics. By operational constraint, we mean the physical or technical constraints that limit the operations which can be realised with a given vehicle and/or a given driver. From this perspective, there are several possibilities, and, to the author's knowledge, no data to assess the prevalence of each of them. In this paper, the following regimes are distinguished: 
I) the round's duration must be lower than a certain time limit $H$, e.g. a driver's workday duration, or half of it if the vehicle has to come back to the origin warehouse in the middle of the day. $H$ is exogenous.

II) receivers expect a lead time lower than $H$; this applies a constraint to the round duration. $H$ is considered exogenous in this paper, although it actually derives from an interaction between the cost of providing a certain lead time, on the supply side, and the willingness to pay for that lead time, on the demand side.

III) receivers must be delivered during a certain time window of duration $H$. This case is notably relevant for wholesale trade, where restaurants, bars or retail stores must be delivered in the morning.

IV) the vehicle has a limited range $L$. While currently seldom relevant, this constraint may become critical in scenarios where alternative vehicles (such as electric vehicles) are considered, and is worth examining.

$H$ need not be equal under regimes I to III. It should also be noted the model is not relevant for all deliveries with short lead time: while the sequence of operation described in Figure 1 is probably relevant for standard parcel delivery, where all shipments are loaded at a given warehouse, it is completely irrelevant for food ordering or other similar services where couriers carry directly meals from restaurants to customers without consolidation.

Note that volume and weight capacity constraints play an apparently very little role in the paper. They are not explicitly represented, but they are present, in the cost parameters for example. However that capacity is seldom the binding constraint in urban logistics, specifically for small shipments: the binding constraints lie elsewhere.

\subsection{The total cost function}

The model consists in a cost function which distinguishes two parts: the warehousing cost, and the transport cost. This section details these cost components and presents the resulting total cost function. The calculations are detailed for regime I only, additional details are available on request.

The warehousing cost function Regarding warehousing costs, there is an abundent operations research literature, but given the level of detail required in this paper, and the lack of data, it is of little use in this paper's context. In this paper, the unit warehousing cost denotes the cost of unloading, sorting, handling, and loading a shipment. Based on textbooks such as (21), warehousing typically requires the main following resources: land use, building, human resources, and equipment. Land use cost will directly depend on the location of the warehouse. The warehousing cost is assumed proportional to the amount of operations, and dependent on location. Location is very simply represented by the distance of the warehouse to the operation area (the area where shipments are delivered and picked up), which is assimilated to the city center: this distance is denoted by $l$. Space is assumed to be continuous: location of highways or other transport infrastructures or the discontinuous and dynamic character of the real estate market are 
ignored. The city is assumed monocentric and radially symetric. As a consequence, the unit warehousing cost per operation is $c_{w}(l)$, with $c_{w}$ a decreasing function.

The transport cost function Operations are realised in sequence during rounds. This raises a difficult issue: finding the optimal round to deliver a given set of locations is a classic operations research problem (the Traveling Salesman Problem), known to be NP-complete. In order to circumvent this difficulty, the approach of (14) is followed. Consider an area of surface $A$, where $F$ operations should be realised over the relevant time period. These $F$ locations are randomly allocated across the area. Let $\delta$ denote the average distance between two consecutive operations: it is inversely proportional to the square root of the density of operations in the area, up to a constant $k$.

$$
\delta=k \sqrt{\frac{A}{F}} .
$$
halved.

Figure 2 belows illustrates Equation (1). From case (A) to case (B), the number of operations is multiplied by four; at the same time, the average intermediate distance is

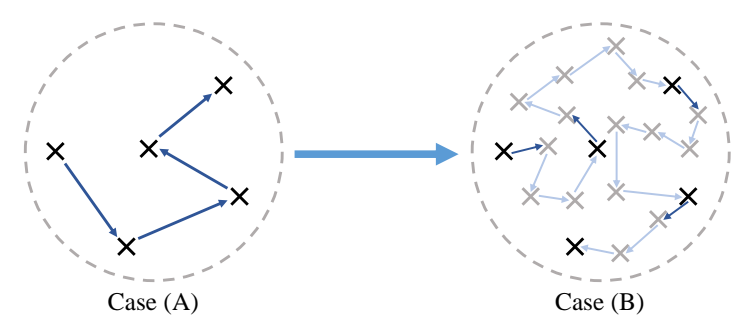

Figure 2: Operations density and intermediate distance.

Now, depending on the regime, let us derive the number of operations which can be realised in one round. Let us focus on regime $I$. Denote by $v_{a}$ (resp. $v_{z}$ ) the average vehicle speed during the approach movement (resp. during intermediate movements), and denote by $h$ the duration of each operation excluding transport (i.e., precisely, the time to load, unload, sign papers, etc.) Denote by $x$ the number of operations. The total round duration, for a given $x$, and given the sequence operation presented in Section 2.2 , is denoted by $d$, and such that:

$$
d=2 \frac{l}{v_{a}}+x\left(h+\frac{\delta}{v_{z}}\right) .
$$

The round duration is constrained: $d=H$. As a consequence:

$$
x=\frac{H-2 l / v_{a}}{h+\delta / v_{z}}
$$

Two comments can be made about this equation. First, $x$ decreases with $l$ : the farther the warehouse, the less operations can be done during one round. This is the 
root of the value of proximity for a warehouse in this situation. Second, this requires that $l<H v_{a} / 2$ : the round duration cannot be lower than the time needed to reach the area and come back.

Let $H_{r}$ denote the in-zone time, i.e. the time actually spent by the vehicle in the operation area:

$$
H_{r}=H-2 l / v_{a} .
$$

Also, let $h_{o}=h+\delta / v_{z}$ denote the duration of an operation, including the time required to travel the intermediate distance between successive operations. Then, Equation (3) can be rewritten as follows:

$$
x=\frac{H_{r}}{h_{o}} .
$$

In order to derive the transport cost function,the distance dependent cost and the time dependent cost of running a vehicle should $b$ distinguished. The distance dependent cost is assumed to increase linearly with distance, up to a coefficient $c_{l}$. It is mainly related to energy consumption and vehicle wear and tear. The time dependent cost is assumed to increase linearly with time, up to a coefficient $c_{h}$. It is related to the capital opportunity cost and the wages. The length of a round is $2 l+\left(H_{r} / h_{o}\right) \delta$, and its duration is $H$. Therefore, the cost of a round is $\left(2 l+\left(H_{r} / h_{o}\right) \delta\right) c_{l}+H c_{h}$.

It is now possible to derive the unit transport cost:

$$
c_{t}=\left(2 l c_{l}+H c_{h}\right) \frac{h_{o}}{H_{r}}+\delta c_{l} .
$$

With some manipulations, replacing $\delta$ with Equation (1), and with $c_{R}=2 l_{c_{l}}+H c_{h}$ :

$$
c_{t}=\frac{c_{R}}{H_{r}} h+\left(\frac{1}{v_{z}} \frac{c_{R}}{H_{r}}+c_{l}\right) k \sqrt{\frac{A}{F}} .
$$

Note that $c_{R}$ increases with $l$, and $H_{r}$ decreases with $l$. As a consequence $c_{t}$ is an increasing function of the distance of the warehouse to the city center, and doubly so: first because when $l$ increases, it is more costly to reach the operation area, second because there is less time to actually proceed to operations in that area.

Also, the transport cost upwards the warehouse was not taken into account, for simplicity. As a matter of fact, if it is assumed to only depend on $l$, it can be accounted for by a modification of $c_{w}$.

The total cost function The total unit cost under regime I, which sums the unit warehousing cost and the unit transport cost, is:

$$
c(l)=c_{w}(l)+\frac{c_{R}}{H_{r}} h+\left(\frac{1}{v_{z}} \frac{c_{R}}{H_{r}}+c_{l}\right) k \sqrt{\frac{A}{F}} .
$$

One component of the cost function decreases with $l$ (the farther from the city center, the lower the warehousing cost), while the other increases with $l$ (the farther from the city center, the higher the unit transport cost). 
Total cost functions under the other regimes Let us first consider the case of regimes $I I$ and $I I I$. Under regime $I I$, the time constraint is modified: instead of having a constraint on the total round duration, there is a constraint on the maximum lead time: the time span between departure from the warehouse and the last delivery cannot exceed $H$ (picking, packing and handling can be included in the constraint.) Under regime $I I I$, the constraint is on the time spent in the operation area: the time span between arrival in and departure from the operation area cannot exceed $H$.

The equations above can be easily generalised to all three regimes. First, the following coefficients are introduced:

$$
\left\{\begin{array}{l}
\rho^{I}=2 \\
\rho^{I I}=1 \\
\rho^{I I I}=0 .
\end{array}\right.
$$

Let $h_{a}=l / v_{a}$ define the time to access the operation zone: Then, modify the in zone time $H_{r}$ given by Equation (4) as follows:

$$
H_{r}=H-\rho h_{a} .
$$

This implies that for $\rho>0$, distance $l$ cannot be larger than $H v_{a} / \rho$. For $\rho=0$ there is no such constraint. Also, modify $c_{R}$ as follows:

$$
c_{R}=2 l c_{l}+\left(H+(2-\rho) h_{a}\right) c_{h}
$$

Then, Equations (7) and (8) remain valid. Note that all other things equal, $c_{t}^{I}(l)>$ $c_{t}^{I I}(l)>c_{t}^{I I I}(l)$, as simple calculations (omitted here) confirm. This behaviour is intuitive: for a given $H$, the constraint is stronger under regime $I$ than under regime $I I$ (resp. regime $I I I$ ), therefore the unit cost is necessarily lower under the latter.

Regime $I V$ works differently: a range constraint is considered. The length of the round must be lower than $L$ :

$$
2 l+x \delta=L .
$$

The transport cost function under regime $I V$ is:

$$
c_{t}(l)=\left(c_{l}+\frac{c_{h}}{v_{z}}\right) \delta+c_{h} h+\left(c_{l}+\frac{c_{h}}{v_{a}}\right) \frac{2 l \delta}{L-2 l} .
$$

Therefore, the total cost function is:

$$
c^{I V}(l)=c_{w}(l)+\left(c_{l}+\frac{c_{h}}{v_{z}}\right) \delta+c_{h} h+\left(c_{l}+\frac{c_{h}}{v_{a}}\right) \frac{2 l \delta}{L-2 l} .
$$

Illustration Figure 3 presents the behaviour of the warehousing, transport and total costs under each regime, with the following parameters: access speed $v_{a}=40 \mathrm{~km} / \mathrm{h}$ ( $25 \mathrm{mph})$, in zone speed $v_{z}=15 \mathrm{~km} / \mathrm{h}(9 \mathrm{mph})$, distance between two operations $\delta=800 \mathrm{~m}(0,5 \mathrm{mile})$, duration of an operation $h=0.2 \mathrm{~h}$, distance dependent cost $c_{l}=1.2 € / \mathrm{km}$ (about $\$ 2,3 / \mathrm{mile}$ ), time dependent cost $c_{h}=20 € / \mathrm{h}$ (about $\$ 38 / \mathrm{mile}$ ), and finally a linear gradient of the unit warehousing cost $c_{w}^{\prime}=-0.15 € / \mathrm{km}$ (about 
$\$ 0.27 / \mathrm{mile}$ ). Without aiming at realism, it amounts to rounds with twenty to thirty operations, for a unit transport cost between 6 to $10 €$ (excluding warehousing costs), which are reasonable orders of magnitude for the last stage of transport of relatively small LTL - but larger than parcels - shipments toward a large urban area.

The following scenarios are then distinguished: one where the total round duration is limited to eight hours (as an example of regime $I$ ), one where deliveries need to be faster than two hours (as an example of regime $I I, H$ was fixed at $1.5 \mathrm{~h}$ to account for order processing), one where the delivery time window is limited to $4 \mathrm{~h}$ (as an example of regime $I I I$ ) and finally one where the round cannot be longer than $70 \mathrm{~km}$ (as an example of regime $I V$ ).

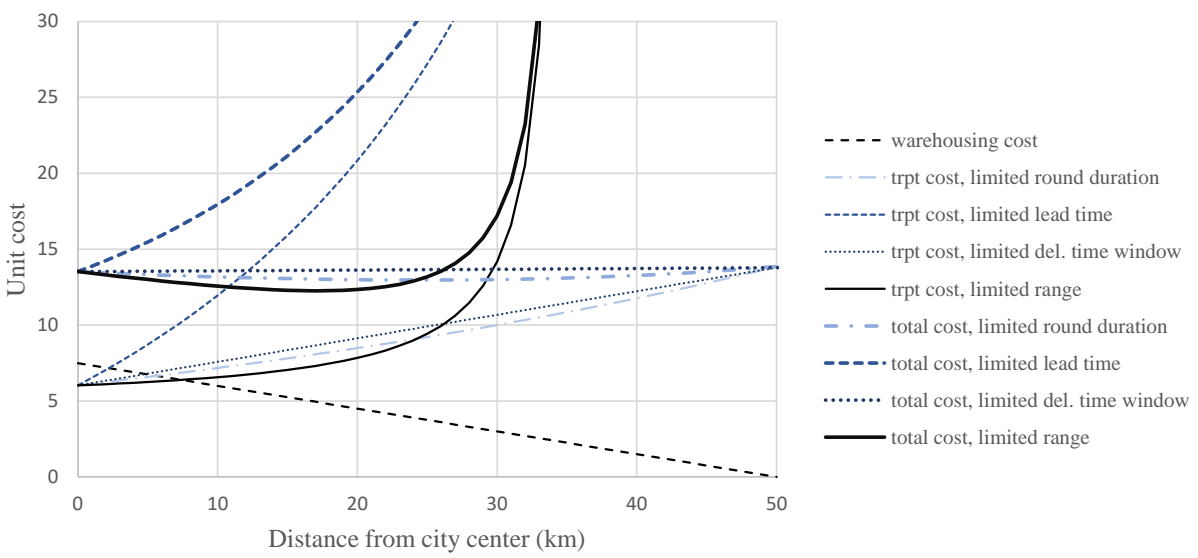

Figure 3: Comparison of cost functions for regimes I-IV

Several mechanisms interact in the results which can be observed in Figure 3. In all cases, getting closer to the center saves on transport cost, but the intensity differs. Theoretically, for a given set of parameters, including $H$, the value of proximity is higher under regime $I$, which is more strongly constrained, than under regimes $I I$ and $I I I$. However, $H$ itself plays a very important role, and the smaller it is, the stronger the constraint. This is why the transport cost increases so quickly with distance in the second case, where the delivery lead time is limited to $1.5 \mathrm{~h}$, with the consequence that it is optimal to be as close to the city center as possible. In this example, regime $I V$ gets to the limit faster than the others.

\section{Private optimum, static comparatives, policy impli- cations}

This section analyses the model's properties. First, the first order conditions of warehouse location optimality are derived (Section 3.1). Then, the influence of the model's parameters on the optimal warehouse location is analysed in Section 3.2. Finally, some 
policy implications are discussed in Section 3.3.

\subsection{Condition of private optimality}

The private optimum is the location which minimises the total unit cost function (8). The social optimum is outside the paper's scope; it is briefly discussed in Section 3.3. The private optimum can be at the center (e.g. regime $I I$ in Figure 3), when transport costs increase so fast that it is optimal to be as close as possible to the operation area; or it can be optimal to be at the periphery, when land rents stop decreasing. An interior solution can also be optimal; in that case it is a necessary condition that $d c / d l=0$.

The differential of $c$ for regimes $I-I I I$ is:

$$
d c=c_{w}^{\prime} d l+\frac{d c_{R} H_{r}-c_{R} d H_{r}}{H_{r}^{2}} h+\left(\frac{1}{v_{z}} \frac{d c_{R} H_{r}-c_{R} d H_{r}}{H_{r}^{2}}\right) \delta .
$$

By noticing that $d c_{R}=2 c_{l} d l+(2-\rho) c_{h} d h_{a}, d h_{a}=d l / v_{a}$ and $d H_{r}=-\rho d l / v_{a}$ and with a few manipulations, the first order condition on the optimality of $l$ for regimes $I$ to $I I I$ is obtained:

$$
0=c_{w}^{\prime}+\left(2 c_{l}+(2-\rho) \frac{c_{h}}{v_{a}}\right) \frac{h_{o}}{H_{r}}+\rho c_{R} \frac{h_{o}}{v_{a} H_{r}^{2}} .
$$

The first order condition for Regime $I V$ is straightforwardly derived from Equation (14). When distinguishing each regime:

$$
\begin{cases}\text { Regime } I & :-c_{w}^{\prime}=2 c_{l} \frac{h_{o}}{H_{r}}+2 c_{R} \frac{h_{o}}{v_{a} H_{r}^{2}}, \\ \text { Regime } I I & :-c_{w}^{\prime}=\left(2 c_{l}+\frac{c_{h}}{v_{a}}\right) \frac{h_{o}}{H_{r}}+c_{R} \frac{h_{o}}{v_{a} H_{r}^{2}}, \\ \text { Regime } I I I & :-c_{w}^{\prime}=\left(2 c_{l}+\frac{2 c_{h}}{v_{a}}\right) \frac{h_{o}}{H_{r}}, \\ \text { Regime } I V & :-c_{w}^{\prime}=\left(2 c_{l}+\frac{2 c_{h}}{v_{a}}\right) \frac{L+4 l}{(L-2 l)^{2}} \delta\end{cases}
$$

As is standard in urban economics, at the optimum, the land rent savings which come from moving one kilometer away from the city center are exactly offset by the additional transport costs. These costs come from two mechanisms: first, the approach and return movements are longer, increasing the unit transport cost; second, they take more time so that less operations can be realised in a round, further increasing the unit transport cost.

\subsection{Comparative statics}

The objective is to analyse the influence of each of the model's parameters on the optimal location of the warehouse. To do so, apply the implicit function theorem to Equations (17). This requires calculating the total differential of each of these equations.

First, consider regimes $I$ to $I I I$. Denote by $\Gamma$ the right-hand side of Equation (16). Denote by $\Gamma_{x}$ the partial differential of $\Gamma$ with respect to variable $x$. Then, the total differential of $\Gamma$ is:

$$
d \Gamma=\Gamma_{l} d l+\Gamma_{c_{l}} d c_{l}+\Gamma_{c_{h}} d c_{h}+\Gamma_{v_{a}} d v_{a}+\Gamma_{v_{z}} d v_{z}+\Gamma_{H} d H+\Gamma_{h} d_{h}+\Gamma_{\delta} d \delta,
$$


Then:

$$
\begin{gathered}
\Gamma_{l}=c_{w}^{\prime \prime}+\frac{4 c_{l} \rho H_{o}}{v_{a} H_{r}^{2}}+2 \frac{(2-\rho) \rho h_{o} c_{h}}{v_{a}^{2} H_{r}^{2}}+\frac{2 \rho^{2} c_{R} h_{o}}{v_{a}^{2} H_{r}^{3}}, \\
\Gamma_{c_{l}}=\frac{2 h_{o}}{H_{r}}+\frac{2 l \rho h_{o}}{v_{a} H_{r}^{2}}, \\
\Gamma_{c_{h}}=\frac{(2-\rho) h_{o}}{v_{a} H_{r}}+\frac{\left(H+(2-\rho) h_{a}\right) \rho h_{o}}{v_{a} H_{r}^{2}}, \\
\Gamma_{v_{a}}=-\frac{(2-\rho) c_{h} h_{o}}{v_{a}^{2} H_{r}}-\frac{\rho c_{R} h_{o}}{v_{a}^{2} H_{r}^{2}}-\frac{2(2-\rho) \rho c_{h} h_{o} l}{v_{a}^{3} H_{r}^{2}}-\frac{2 c_{l} h_{o} \rho l}{v_{a}^{2} H_{r}^{2}}-\frac{2 \rho^{2} c_{R} h_{o} l}{v_{a}^{3} h_{r}^{3}}, \\
\Gamma_{v_{z}}=-\frac{2 c_{l} \delta}{H_{r} v_{z}^{2}}-\frac{(2-\rho) c_{h} \delta}{v_{a} H_{r} v_{z}^{2}}-\frac{\rho c_{R} \delta}{v_{a} H_{r}^{2} v_{z}^{2}}, \\
\Gamma_{H}=\frac{\rho h_{o} c_{h}}{v_{a} H_{r}^{2}}-\frac{2 c_{l} h_{o}}{H_{r}^{2}}-\frac{(2-\rho) c_{h} h_{o}}{v_{a} H_{r}^{2}}-\frac{2 \rho c_{R} h_{o}}{v_{a} H_{r}^{3}}, \\
\Gamma_{h}=\frac{2 c_{l}}{H_{r}}+\frac{(2-\rho) c_{h}}{v_{a} H_{r}}+\frac{\rho c_{R}}{v_{a} H_{r}^{2}}, \\
\Gamma_{\delta}=\frac{2 c_{l}}{H_{r} v_{z}}+\frac{(2-\rho) c_{h}}{v_{a} H_{r} V_{z}^{2}}+\frac{\rho c_{R}}{v_{a} H_{r}^{2} v_{z}} .
\end{gathered}
$$

The sign of $\Gamma_{l}$ depends on the sign of $c_{w}^{\prime \prime}$. Let us assume that the land rent is convex, or linear; this implies that $\Gamma_{l}>0$. The partial differentials of $\Gamma$ with respect to $c_{l}, c_{h}$, $h$ and $\delta$ are clearly positive. The partial differentials of $\Gamma$ with respect to $v_{a}$ and $v_{z}$ are negative. Some simple calculations can show that the partial differential of $\Gamma$ with respect to $H$ is negative. By application of the implicit function theorem, provided $\Gamma_{l} \neq 0$, the variation of $l$ with any parameter $x$ is given by:

$$
\frac{d l}{d x}=-\frac{\Gamma_{x}}{\Gamma_{l}} .
$$

It is possible to conclude regarding the influence of the various model's parameters on the distance of the warehouse to the city center:

- when the unit transport costs $c_{h}$ or $c_{l}$ increase, the optimal warehouse distance decreases: the cost increase is partially offset by bringing the warehouse closer to the city center;

- when the duration of each operation $h$ increases, the optimal warehouse distance decreases.

- when $H$ increases (i.e. the time constraint on the operations is relaxed), the optimal warehouse distance increases. Symmetrically, if $H$ gets small (for example to provide faster deliveries), then the value of proximity increases.

- when the access or in zone speeds $v_{a}$ and $v_{z}$ increase, the optimal warehouse distance increases: better speeds participate in relaxing the operational constraints; being close to the city center is less valuable. 
- when the density of operations increase (i.e. when $\delta$ decreases), then the optimal warehouse distance increases: when the demand is higher, operations are more efficient, proximity is less necessary.

The last point is of particular importance: while logistic sprawl can be and has been explained by many different causes, including land rent changes, one important conclusion of this paper is that changes in demand (especially the strong and sustained increase of the demand for e-commerce) probably contributes to explain the observed dynamics. Note that the expression logistic sprawl can refer to a number of distinct spatial dynamics: in this case, we discuss the spreading of warehouses from the city center, but not the spreading or clustering of warehouses relative to each other. The very simplified representation of space in the model makes it unsuitable for the investigation of this more complicated phenomenon.

These conclusions apply to all three regimes, from $I$ to $I I I$. Comparing the elasticities of $l$ with respect to the other parameters is a more involved task: remind that $H_{r}$ and $c_{R}$ also depend on $\rho$. This comparison is outside the paper's scope. Regarding regime $I V$, the results are not detailed. The model's behaviour is rather similar, except that $\Gamma_{v_{z}}=\Gamma_{h}=\Gamma_{\delta}=0$ : the corresponding variables have no influence on the optimum location (under the assumption that the autonomy is truely exogenous). However, even though the signs of the influence of each parameter on $l$ is unchanged, the intensity of the variation will vary. These regimes will not react similarly to given changes in the parameters: urban logistics is a heterogeneous system; and this heterogeneity comes, among other things, from the diversity of constraints under which the agents operate.

Also outside the scope of this paper is an in-depth discussion of the influence of the various model's parameters on the total cost function. Nevertheless, any parameter which has an influence on $l$ has an influence on total costs. More precisely, when a parameter decreases $l$, it increases the total cost, and conversely. Let us illustrate this point with the case of fast deliveries (Figure 4).

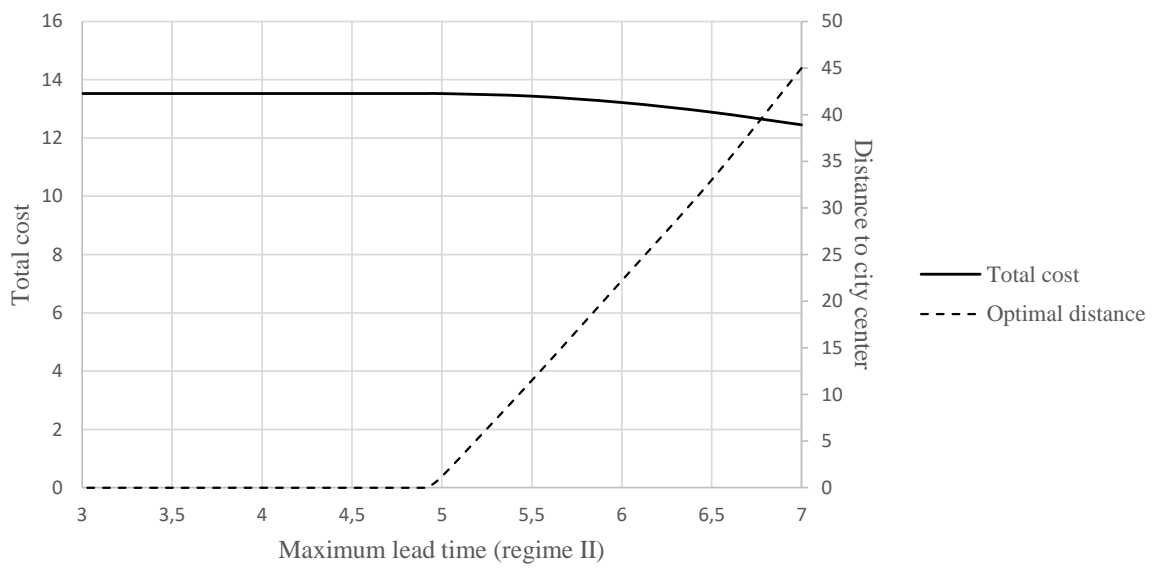

Figure 4: Distance to center and total cost as function of lead time under regime $I I$. 
This figure confirms the discussion above: when $H$ decreases, it is more efficient to get closer to the city center. However the total cost increases: this is a classic microeconomic mechanism where it is possible to adapt to a price increase or to a constraint strengthening, but not to the point where the cost increase is fully offset. Note that this discussion suffers from an important limitation: demand is assumed exogenous here. With endogenous demand and, as it will be seen later, economies of scales, these statements may not hold. In addition, if $H$ decreases, opportunities for massification will decrease, and $\delta$ will increase. This also does limit the conclusions, and warrants further research.

\subsection{Some policy implications}

Urban logistics is a well known source of externalities, as discussed in the introduction. Standard microeconomic theory recommends that these externalities be internalised. The main externalities associated with urban logistics are associated with the distances covered and, to certain extent, to the duration of presence within urban areas as well (e.g. noise, pollution, congestion generated by illegal parking, etc.) Internalising these externalities (e.g. through tolls) would amount to increase $c_{h}$ and $c_{l}$. This would decrease the optimal warehouse location, getting it closer to the city center.

It is possible to take a different perspective: in a second best world, where it can be very difficult to internalise all externalities, which planning actions could help improve social welfare? In this case, actions that would help warehouses to locate closer to the city center would probably be welfare improving. This topic needs further investigation, and a in-depth analysis of the issue requires endogenous demand. However, the model contributes to illustrate how planning should be considered as an instrument of urban logistics policy.

Other policy actions can be examined with this type of modelling approach. Consider policies such as enforcing delivery time-windows (forbidding deliveries outside a certain time window in a certain zone), or supporting off-hour deliveries (22). Under regime $I I I$, reducing $H$ is costly; it also causes the optimal distance to decrease. The warehouse movement can offset part of the cost increase. However, if warehouses cannot move back towards the city center, then the policy will be very costly. Such policies are probably worth being accompanied with synergistic land-use planning initiatives.

A third policy implication is directly related to the structure of the cost function. Equation (8) is a unit cost function. Denote by $C$ the total cost function: it is equal to the unit cost $c$ times the demand $F$ :

$$
C=F c_{w}(l)+F \frac{c_{R}}{H_{r}} h+\left(\frac{1}{v_{z}} \frac{c_{R}}{H_{r}}+c_{l}\right) k \sqrt{A F}
$$

Let us calculate the marginal social cost of an additional receiver. According to the envelop theorem, $l$ can be assumed fixed in the calculation:

$$
\frac{\partial C}{\partial F}=c_{w}(l)+\frac{c_{R}}{H_{r}} h+\frac{1}{2}\left(\frac{1}{v_{z}} \frac{c_{R}}{H_{r}}+c_{l}\right) k \sqrt{\frac{A}{F}} .
$$


2 the marginal external social cost:

$$
m e s c=\frac{\partial C}{\partial F}-c=-\frac{1}{2}\left(\frac{1}{v_{z}} \frac{c_{R}}{H_{r}}+c_{l}\right) k \sqrt{\frac{A}{F}}<0 .
$$

When demand increases in a given area, the density of operations increases. Therefore, there are economies of scale, with an impact on cost similar to the Mohring effect in public transport (23), where more passengers induce an increased frequency, to the benefit of all. These economies of scale are also a possible source of economies of agglomeration (in (24), the authors find that the sector which aggregates transport, storage and communication exhibits particularly large economies of agglomeration.) For public transport, the Mohring effect is often raised as a motivation for subsidisation. Should urban logistics be subsidised? And how should it be? What are the interaction between this positive externality and the other, negative externalities? This topic warrants a dedicated discussion, which is unfortunately outside this paper's scope.

\section{Conclusions}

The model presented in this paper models the optimal location of a warehouse in an urban area, as the result of a trade off between transport costs and warehouse costs. The model is theoretical and analytical. Close attention is paid to represent the operational constraints of transport. In order to represent the heterogeneity of urban logistics, different contraints are distinguished: constraints on round duration, on lead time, on delivery time window, and on vehicle range.

Despite its simplicity, the model yields a number of non trivial implications. First, the role of demand density in the structure of cost is highlighted. In particular, its role as a possible contribution to logistic sprawl is identified. Second, the paper identifies economies of scale in urban logistics, with possibly important consequences in terms of public policy which remain to be fully investigated. Third, the paper briefly addresses how land-use planning aimed at urban logistics can probably be a relevant transport economics policy instrument: in the difficulty to internalise directly many of the externalities of urban freight transport, planning warehouse location can be an indirect way to reach policy objective. Finally, this model is an addition to the modelling toolset for the analysis and assessment of urban public policy. The level of detail in the representation of the transport cost structure allows a detailed analysis of the consequences of a varied range of policies.

Several important features lack in the model: endogenous demand, choice of receivers (firms or residents) between distinct channels, market structure, a better representation of warehousing costs. Additional data about what type of constraint is binding for whom would also be a significant step towards a better knowledge of urban logistics. These limitations are directions for future research.

Acknowledgements The author would like to thank many colleagues, especially Martin Koning (IFSTTAR), and anonymous reviewers for comments which have proved 
very helpful in improving the paper. The author remains responsible for the article, its conclusions, and any potential mistak. This article is based on research realised in the framework of the European H2020 CITYLAB research program.

Author contribution statement The author confirms sole responsibility for the following: study conception and design, analysis and interpretation of results, and manuscript preparation. In addition, all the figures in the paper are the author's own elaboration.

\section{References}

(1) Taniguchi, E., and Thompson, R. G., City logistics: Mapping the future; CRC Press: 2014.

(2) Macharis, C., and Melo, S., City distribution and urban freight transport: multiple perspectives; Edward Elgar Publishing: 2011.

(3) McKinnon, A. (2009). The present and future land requirements of logistical activities. Land Use Policy 26, S293-S301.

(4) Raimbault, N. Gouverner le développement logistique de la métropole: périurbanisation, planification et compétition métropolitaine, le cas du bassin parisien et éclairages étrangers., Ph.D. Thesis, Université Paris-Est, 2014.

(5) Coulombel, N., Dablanc, L., Gardrat, M., and Koning, M. (2018). The environmental social cost of urban road freight: Evidence from the Paris region. Transportation Research Part D: Transport and Environment 63, 514-532.

(6) Statistica Retail e-commerce sales in the United States from 1st quarter 2009 to 1st quarter 2018. https: / / www . statista. com/statistics/187443/ quarterly-e-commerce-sales-in-the-the-us/.

(7) Agatz, N. A., Fleischmann, M., and van Nunen, J. A. (2008). E-fulfillment and multi-channel distribution - A review. European Journal of Operational Research 187, 339-356.

(8) Dablanc, L., Morganti, E., Arvidsson, N., Woxenius, J., Browne, M., and Saidi, N. (2017). The rise of on-demand 'Instant Deliveries' in European cities. Supply Chain Forum: An International Journal 18, 203-217.

(9) Dablanc, L., and Ross, C. (2012). Atlanta: a mega logistics center in the Piedmont Atlantic Megaregion (PAM). Journal of transport geography 24, 432-442.

(10) Dablanc, L., Ogilvie, S., and Goodchild, A. (2014). Logistics sprawl: differential warehousing development patterns in Los Angeles, California, and Seattle, Washington. Transportation Research Record: Journal of the Transportation Research Board, 105-112.

(11) Sakai, T., Kawamura, K., and Hyodo, T. (2015). Locational dynamics of logistics facilities: Evidence from Tokyo. Journal of Transport Geography 46, 10-19. 
(12) Dablanc, L., Liu, Z., Koning, M., Klauenberg, J., de Oliveira, L. K., Blanquart, C., Combes, F., Coulombel, N., Gardrat, M., Heitz, A., et al. Observatory of Strategic Developments Impacting Urban Logistics (2017 version)., IFSTTARInstitut Français des Sciences et Technologies des Transports, de l'Aménagement et des Réseaux, 2017.

(13) Andriankaja, D. Le "desserrement logistique", quelle responsabilité dans l'augmentation des émissions de $\mathrm{CO} 2$ des activités de messagerie., Ph.D. Thesis, IFSTTAR/Université Paris Est, 2014.

(14) Daganzo, F. F., Logistics Systems Analysis, Fourth; Springer: Berlin, 2005.

(15) Baumol, W. J., and Vinod, H. D. (1970). An Inventory Theoretic Model of Freight Transport Demand. Management Science 16, 413-421.

(16) Combes, F., and Tavasszy, L. A. (2016). Inventory theory, mode choice and network structure in freight transport. European Journal of Transport and Infrastructure Research (EJTIR), 16 (1) 2016.

(17) Serouge, M., Patier, D., Routhier, J.-L., and Toilier, F. Enquête Marchandises en Ville réalisée en Ile-de-France entre 2010 et 2013, Rapport final de convention 09 MT CV 46, LET, pp. 126., tech. rep., 2014.

(18) Beziat, A., Launay, P., and Toilier, F. In 6th Metrans International Urban Freight Conference, Long Beach, CA, USA, 2015.

(19) Beziat, A. Approche des liens entre transport de marchandises en ville, formes urbaines et congestion - Le cas de l'Île-de-France., Ph.D. Thesis, IFSTTAR/Université Paris Est, 2017.

(20) Routhier, J.-L., Segalou, E., and Durand, S. Mesurer l'Impact du Transport de Marchandises en Ville : le Modèle de Simulation FRETURB v1., Report for the French Program Marchandises en Ville, 2002.

(21) Rushton, A., Croucher, P., and Baker, P., The handbook of logistics and distribution management: Understanding the supply chain; Kogan Page Publishers: 2014.

(22) Holguin-Veras, J., Ozbay, K., Kornhauser, A., Brom, M., Iyer, S., Yushimito, W., Ukkusuri, S., Allen, B., and Silas, M. (2011). Overall impacts of off-hour delivery programs in New York City Metropolitan Area. Transportation Research Record: Journal of the Transportation Research Board, 68-76.

(23) Mohring, H. (1972). Optimization and scale economies in urban bus transportation. The American Economic Review 62, 591-604.

(24) Graham, D. J., and Kim, H. Y. (2008). An empirical analytical framework for agglomeration economies. The Annals of Regional Science 42, 267-289. 